\title{
COMPETÊNCIA DE LEITURA E ESCRITA EM UNIVERSITÁRIOS
}

\section{ARTIGO ORIGINAL}

ANDRADE, Heidy Elizia Sauer ${ }^{1}$

ANDRADE, Heidy Elizia Sauer. Competência de leitura e escrita em universitários. Revista Científica Multidisciplinar Núcleo do Conhecimento. Ano 04, Ed. 10, Vol. 08, pp. 165-180. Outubro de 2019. ISSN: 2448-0959, Link de acesso: https://www.nucleodoconhecimento.com.br/educacao/universitarios

\section{RESUMO}

O artigo apresenta as competências de leitura que todo aluno do Ensino Superior deveria possuir. As dificuldades no desenvolvimento das competências de leitura e escrita textual tem se mostrado um grande desafio as instituições universitárias. No entanto, os alunos estudam por no mínimo 12 anos antes de ingressar no ensino superior, e, ainda assim possuem dificuldades para compreender textos simples, então ao adentrar à universidade deparam-se com os textos técnicos e científicos, que são mais elaborados. Todavia, fruto de uma deficiência já existente, estes jovens não conseguem êxito na leitura e produção escrita, e muitas vezes, acabam abandonando o mundo acadêmico sem saber ao certo qual motivo os levou a tal. Além da pesquisa bibliográfica, se apresentam também dados obtidos em uma pesquisa de natureza aplicada, que teve como amostra populacional 60 alunos que cursam o terceiro semestre da graduação na Faculdade de Sinop (FASIPE). Ao final, pode-se observar que falta a estes alunos repertório de leitura, prática constante da escrita, e, retomada do texto, com o objetivo de aprimorá-lo.

Palavras-chave: Leitura, escrita, universitários.

\footnotetext{
${ }^{1}$ Mestranda em Educação pela Universidad del Atlântico, pós-graduada em Docência pela Faculdade de Sinop (FASIPE), graduada em Licenciatura Plena em Letras pela Universidade do Estado de Mato Grosso (UNEMAT).
} 


\section{INTRODUÇÃO}

A cada ano o governo brasileiro vem tentando melhorar os índices educacionais da população. A obrigatoriedade de manter crianças e jovens estudando tem contribuído significativamente para o aumento destes índices. Como consequência do aumento no número de concluintes do ensino médio, cada vez mais pessoas chegam às universidades, e, não encontrando vagas nas instituições de ensino superior públicas, acabam buscando uma vaga em instituições privadas.

Dos alunos que chegam ao ensino superior, muitos não estão preparados para as rotinas de estudo que a graduação exige. Tem se percebido no meio acadêmico, que, muitos destes alunos apresentam sérios problemas de leitura e escrita, e que estes problemas dificultam a produção científica almejada pelas instituições e professores do ensino superior. De acordo com Marquesin, Benevides e Baptista (2011, p. 10) "o letramento pode ser considerado um processo complexo, que quase sempre é visto como associado à alfabetização".

Com vistas a diminuir a incidência de reprovação de acadêmicos que estão em fase de conclusão da graduação, algumas faculdades tem exigido de seus alunos a correção das monografias por um professor com formação na área de letras. Assim, tenho recebido nos últimos semestres alguns textos, a fim de realizar neles, a devida correção.

Os problemas encontrados nestes textos são variados, mas entre eles pode-se citar: os problemas com as normas gramaticais da língua padrão, a repetição constante das ideias apresentadas, o pequeno aprofundamento na temática desenvolvida, a falta de coerência nos argumentos apresentados e a falta de coesão no texto.

Observando esta deficiência de escrita nos alunos do nível superior, surgiu a ideia de investigar as causas deste problema, e, formas de resolvê-lo. Assim, foi iniciada a pesquisa que deu origem a este artigo, constituída de três partes: primeira - leitura de textos científicos que falassem sobre o assunto; segunda - aplicação de questionário junto a alunos do nível superior; terceiro - análise dos dados coletados. 
A coleta de dados, por meio de questionário foi realizada no dia 17 de junho de 2013, na Faculdade de Sinop (FASIPE) e teve como amostra cursistas do $3^{\circ}$ semestre dos cursos de administração, direito e enfermagem.

\section{LEITURA E ESCRITA: DESAFIOS À EDUCAÇÃO SUPERIOR}

Mesmo conhecendo a gramática e possuindo um repertório razoável de leitura, muitos alunos concluem o ensino médio e chegam ao ensino superior sem conseguir ler e escrever. Segundo Brás ${ }^{[2]}$ (p. 2)

O desenvolvimento da consciência sobre os processos de ler e escrever é, no mundo hodierno, imprescindível. A leitura, a compreensão e a produção de textos são, conforme pesquisas recentes, a grande deficiência do ensino no Brasil. A maioria dos jovens egressos do ensino médio sai da escola sem saber ler, interpretar, ter opinião crítica e, consequentemente, sem produzir bons textos. Assim sendo, elaborar um texto de forma pessoal, articulada, crítica e em linguagem culta não é tarefa fácil para o aluno, mesmo sendo um estudante universitário. Isso tudo contraria o procedimento essencial nos Cursos de Graduação, já que as habilidades de leitura e de escrita são indispensáveis enquanto alunos e como futuros profissionais.

O fato é que muitos destes alunos chegarão ao final do Ensino Superior sem que este problema seja resolvido, ou seja, concluirão o curso superior lendo e escrevendo com severas dificuldades. É claro que não se pode responsabilizar as Instituições de Ensino Superior (IES) por esta problemática, até porque este problema advém do ensino básico, como afirmam Fontana e Porsche (2011) o problema não está somente na prática pedagógica do professor e também não está somente no aluno, mas do ensino de Língua Portuguesa que deve ser mais contextualizado. Contudo, acreditase que cabe as IES procurarem soluções, a fim de que seus alunos concluam a graduação totalmente alfabetizados, no sentido mais amplo da palavra, como informa Luft in Fontana e Porsche (2011, p. 29).

E, para mim, alfabetizado não é quem assina o nome, talvez embaixo de um documento, mas quem assina um documento e consegue ler e entender. A imensa maioria dos ditos meramente alfabetizados não está nesta lista - um dado melancólico para qualquer país civilizado. 
Ao tomar-se a informação acima como verdadeira, consegue-se compreender que é preciso um esforço conjunto, a fim de reverter a situação de ineficiência dos alunos na leitura e na escrita, com o objetivo de formar melhores profissionais para o mercado de trabalho.

\subsection{O PROCESSO DA LEITURA}

O processo da leitura é complexo, e talvez por isso muitas pessoas, das que se dizem alfabetizadas, não conseguem contemplá-lo. Ler é mais do conseguir decodificar algumas letras, é fazer com que estas letras/palavras produzam um sentido, como reflete Cavalcanti (2010, p. 13):

Ler é construir sentidos. [...] Assumir a leitura como construção de sentidos significa assumir uma dada concepção de língua, de texto e, também de leitor (e produtor de textos). Se se concebe a língua como código, não há como falar em construção de sentidos. Isto porque em uma língua-código os sentidos já estariam prontos, "esperando" o leitor para recuperá-los. O papel deste último, como se vê, é reduzido a de um mero decodificador de mensagens. De forma diferente, a concepção dialógica de linguagem implica a assunção de leitor ativo, um sujeito que interage, via texto, com outras vozes, dentre elas a voz de quem produz o texto objeto de leitura. Aqui cabe a afirmação ler é construir sentidos.

Ao se conceber a leitura como um processo de construção de sentidos, começa-se a perceber que os textos possuem diversas vozes, a do escritor, a do leitor, e aquela que está além do que foi dito, sobre esta leitura Cavalcanti (2010, p. 14) faz a seguinte observação:

Chamo essa leitura de leitura autoral, uma leitura significativa, não a melhor ou a "correta", mas aquela que permite olhar os textos para além do que manifestam de forma explícita em sua superfície. Isso porque a maior parte dos sentidos que podem ser atribuídos a um texto está submersa, no nível do implícito.

Esta visão traz a discussão o papel do leitor que ao contrário do que se pensa deve ser totalmente ativo, pois ele (leitor) interage com o texto e conduz a leitura a um processo dinâmico resultante dessa interação com o texto, com o autor, com sua percepção de mundo e também de sua interação com outros textos. Assim, conforme 
o nível de conhecimento do leitor irá mudar seu modo de perceber um texto, e a cada nova leitura de texto, esse mesmo leitor também produzirá novas leituras de um mesmo texto. Estas leituras, por sua vez, produzirão um indivíduo muito mais atento a sua existência e as mudanças existentes ao seu redor, como informam Fontana e Porsche (2011, p. 27).

Tudo indica que aquele que cultiva o hábito da leitura tende a aumentar a capacidade de entendimento e de reflexão criteriosa sobre a complexidade do mundo. Saviani (2002) sustenta que ler é muito mais do que conhecer, ler é pensar. E não há poder maior no mundo do que o poder do pensamento.

Para que exista comunicação entre um texto e o leitor, certos padrões linguísticos precisam ser observados, pois se isso não ocorrer podem ser aferidas ao texto sérios problemas de compreensão e este texto pode perpassar ideias opostas as desejadas. Entretanto, muitos acadêmicos não dedicam parte de seu tempo a leitura, e, isto resulta numa dificuldade ainda maior na hora de escrever, pois eles desconhecem os padrões de escrita, padrões estes que podem ser aprendidos com a própria leitura, como discutem Fontana e Porsche (2011, p. 15)

A convivência com textos de uso formal, ou escrita formal propicia o aprendizado dos próprios padrões de escrita formal. Todavia, como os alunos leem muito pouco também enfrentam um problema que é consequência da falta de leitura: a dificuldade em escrever.

Além disso, o mundo globalizado tem exigido daqueles que se inserem na sociedade uma amplitude de conhecimento sobre o próprio mundo. Neste aspecto, a leitura poderia ser uma fonte inesgotável para se adquirir conhecimento, contudo, muitos dos alunos das IES preferem adquirir conhecimento por vias mais rápidas, como a televisão e a internet. Cavalcanti (2010) observa que estes meios muitas vezes não repassam informações confiáveis, ou então, quando o fazem de forma fidedigna, não conseguem repassar todos os detalhes sobre os fatos, visto a necessidade destes meios de produzirem notícias em grande escala e com rapidez.

Outrossim, há que se saber que o processo de leitura é uma busca constante pelo significado, de forma especulativa e construtiva, realizando as seleções que se 
fizerem pertinentes em um determinado momento, pois ler é uma atividade que auxilia a aprendizagem.

\subsection{ESCREVER - HABILIDADE OU PRÁTICA?}

Circula entre os estudantes a falsa ideia de que escrever é uma habilidade concedida a poucos, e, por ser um dom, poucas pessoas seriam capazes de desenvolvê-la. Esta ideia, no entanto, foi muitas vezes desmentida por grandes escritores, como Graciliano Ramos in Cavalcanti (2010, p. 85) ao afirmar:

Deve-se escrever da mesma maneira como as lavadeiras lá de Alagoas fazem seu ofício. Elas começam com uma primeira lavada, molham roupa suja na beira da lagoa ou do riacho, torcem o pano, molham-no novamente, voltam a torcer. Colocam o anil, ensaboam e torcem uma, duas vezes. Depois enxaguam, dão mais uma molhada, agora jogando a água com a mão. Batem o pano na laje ou na pedra limpa, e dão mais uma torcida e mais outra, torcem até não pingar do pano uma só gota. Somente depois de feito tudo isso é que elas dependuram a roupa lavada na corda ou no varal, para secar. Pois quem se mete a escrever devia fazer a mesma coisa. A palavra não foi feita para enfeitar, brilhar como ouro falso; a palavra foi feita para dizer.

Como Graciliano Ramos enfatiza, escrever é um trabalho, exige esforço e dedicação. E, apesar dos universitários chegaram ao Ensino Superior após passarem cerca de 9 anos estudando (se somados ensino fundamental e médio) eles demonstram desconhecer esta propriedade da escrita. Assim, pode-se afirmar que o sistema educacional brasileiro tem descumprido o que seria uma de suas obrigações básicas: ensinar o aluno a escrever. Sobre esta prática Cavalcanti (2010, p. 86) faz a seguinte observação:

A escola, instituição responsável pelo ensino da escrita, pouco contribui para o desenvolvimento da competência textual dos alunos. Por competência textual entendemos a capacidade de produzir textos em diferentes gêneros, adequados a múltiplas situações. Ao priorizar atividades artificiais, como exercícios e "redações", a escola reforça uma compreensão inadequada da produção escrita, a de que seria resultante de atividades artificiais como essas. Muitas vezes, por não conseguir um bom desempenho quando se trata de escrever textos de verdade, isto é, que são produzidos e circulam fora da escola, o aluno passa a acreditar que não consegue escrever porque não tem o "dom da escrita". 
Ao entrar no Ensino Superior o aluno continua acreditando que não sabe escrever. Contudo, o ensino superior exige dos acadêmicos a produção escrita, e, como muitos se sentem incapazes de realizá-la, acabam abandonando o curso nos primeiros semestres. Outros alunos por sua vez, recorrem ao uso de macetes, que auxiliem na produção escrita. Não se pode dizer que o uso de regras e macetes não auxiliam a produção escrita, entretanto, somente o aprendizado destes não é suficiente, pois as regras não dão conta da complexidade da escrita. Além disso, conceber uma boa escrita ao uso eficiente de regras gramaticais e a uma letra legível cria uma concepção redutora de escrita. Escrever é um processo, que demanda várias etapas, inclusive a reescrita, que é de fundamental importância, como informa Cavalcanti (2010, p. 89)

O "enfrentamento" da folha em branco, da tela do computador, é apenas parte de um processo que se inicia bem antes, com pesquisas e leituras, e passa por outros momentos que vão desde a revisão até a reescrita e edição do texto. Nesse percurso, é comum a participação de outros leitores, além do próprio autor, que dão ideias, sugerem modificações, que podem ser acolhidas ou não. Trata-se, assim, de um conjunto de práticas, um processo bastante complexo, que em nada lembra um momento único, do qual resultaria o texto pronto e acabado.

Com a descoberta de que escrever demanda trabalho árduo, muitas pessoas acabam se afastando do propósito de escrever, pois é mais fácil acreditar que não possuem tal "dom", do que exercitá-lo. Assim, no contexto universitário, há a tentativa acadêmica de escrever o mínimo necessário, apenas para conseguir o diploma. Como o tempo disponível para a grande maioria dos alunos é curto, e não se deseja fazer muito esforço, surgem os textos plagiados e/ou comprados, encontrados facilmente nas mídias eletrônicas.

Por outro lado, ao mesmo passo que as mídias facilitam a não escrita, elas também propiciam um aumento no número de escritores de textos informais. Estas escrituras usam-se de meios como o chat, correio eletrônico e blog, entre outros, para se comunicar. Todavia, não se sabe até que ponto os escritores destas mídias conseguem produzir textos mais formais, como um trabalho de pesquisa científica, por exemplo. Cabe dizer que a avaliação de um texto formal bem escrito decorre de vários 
fatores, pois a noção de um bom texto varia conforme a época em que ele é escrito e também conforme o gosto de quem o lê, nas palavras de Cavalcanti $(2010$, p. 97)

[...] considerar um texto bem escrito é uma questão que envolve fatores de diferentes ordens. Como dissemos, para refletir sobre esses fatores, entender as razões que levam à emergência e modificação dos gêneros, é preciso analisar as condições específicas e as finalidades das diferentes esferas de atividades, os lugares sociais, e as representações que circulam nesses lugares.

Por isso, a autora (idem) afirma que é de comum entre a maioria dos linguistas e professores de língua portuguesa a consciência de que um bom texto é aquele que consegue passar as informações desejadas pelo seu autor, pois a forma utilizada para fazê-lo é mera formalidade, necessária sim, mas que pode sofrer alterações com o passar dos anos.

\subsection{RETOMANDO O TEXTO PARA REESCREVÊ-LO}

A escrita surgiu junto a necessidade dos povos primitivos se comunicarem, e emergiu junto ao crescimento do comércio e da política, perpassando as gerações posteriores a sua cultura. A fim de facilitar o processo de escrita, surgiram normas para realizá-la. Contudo, é de senso comum daqueles que trabalham a linguagem que a escrita envolve uma amplitude de informações, por isso, Cavalcanti (2010, p. 97) ressalta que "[...] não basta seguir "receitas" ou acatar as famosas "dicas": trata-se de uma prática que se aperfeiçoa com a própria prática, com a escrita diária. [...]”.

Deste modo, a prática da escrita deveria incluir a leitura e reescrita do texto, a fim de lapidá-lo. Cavalcanti (2010) afirma que o momento da reescrita é indispensável ao processo da escrita, pois neste momento o autor se colocaria na posição de leitor e avaliaria o seu texto, podendo acrescentar argumentos, excluir informações, modificar, enfim melhorar o que já escreveu. Entretanto, o contexto escolar e universitário não costuma praticar a reescrita de textos. Isto acontece principalmente por dois fatores: primeiro, devido ao despreparo do profissional da educação; segundo, devido ao tempo insuficiente que estes profissionais possuem para realizar a correção textual. 
Além disso, a reescrita precisa ser vista de um modo diferente do habitual. Hoje, ela costuma ser associada ao propósito de se higienizar o texto, corrigindo erros de ortografia e concordância, entre outros, conforme Cavalcanti (2010, p. 161)

[...] Não há comentários sobre a seleção de argumentos, a adequação do texto a seu público, se o tom está adequado ao propósito comunicativo do texto e outras observações que promoveriam a melhora do texto, seu enriquecimento, observações essas que só podem ser feitas por um professor capaz de avaliar se o aluno sabe interpretar adequadamente as condições de produção de seus texto e não por um professor preocupado apenas em "caçar erros".

Este tipo de correção poderia contribuir de forma mais significativa com o texto, pois permitiria ao aluno a observação de suas falhas. Ela deveria incluir o apontamento do que deve ser refeito e de que modo o escrevente pode fazê-lo. A consequência deste tipo de trabalho seria uma melhora significativa na qualidade dos textos produzidos, $e$ poderia levar também a um aumento na produção literária e científica de acadêmicos. Embora já tenha sido comprovada a eficácia deste método, ele ainda não é utilizado, como informa Cavalcanti (2010, p. 168)

Há uma resistência, tanto de professores como de alunos, a retomar ao texto produzido, como se este não precisasse de outras versões além da primeira, considerada definitiva. Para Dahlet, a ausência da etapa de reelaboração do texto, verificada no processo de escrita da maioria dos sujeitos por ele pesquisados, pode ser explicada pela dificuldade que os escreventes têm de se distanciarem do próprio texto, em ocuparem a posição de leitores a fim de avaliar o que escreveram. Trata-se de uma dificuldade que a escola acaba não conseguindo eliminar, uma vez que, depois de terminada a "tarefa" o texto produzido não é analisado e reescrito (e muitas vezes não é sequer lido pelo professor).

Neste sentido, é necessário que exista um esforço maior por parte dos que trabalham na educação, a fim de que eles discutam com seus alunos a importância de se retomar um texto, realizando observações pertinentes, que vão além da ortografia.

\section{COLETA E ANÁLISE DOS DADOS}

A coleta dos dados foi realizada por meio de questionário estruturado, contendo perguntas abertas e fechadas. O questionário foi aplicado no dia 17 de junho de 2013, 
e teve como participantes: 25 alunos do curso de direito; 22 do curso de administração; e 13 do curso de enfermagem. Todos eles alunos na FASIPE - Faculdade de Sinop, cursando na época o $3^{\circ}$ semestre do respectivo curso. O objetivo deste questionário era identificar o perfil de escrita e leitura destes acadêmicos.

A primeira pergunta indagava: Você gosta de ler? O gráfico número 1 representa as respostas obtidas.

\section{GRÁFICO 1}

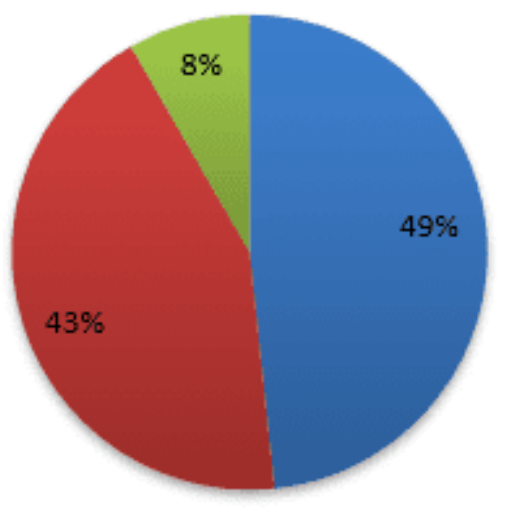

sim

um pouco

não

Fonte: Própria

Observou-se que, dos acadêmicos entrevistados 49\% gostam de ler. Assim, toma-se a premissa de que os alunos que mais possuem dificuldade para escrever são aqueles que não leem. Embora a leitura não apresente fator decisivo na hora de escrever, ela auxilia a construção de argumentos e também aprimora o conhecimento dos gêneros textuais, por isso Motta (2010, p. 12) afirma que "Sabendo-se que quem lê pouco, lê mal, devemos priorizar conteúdos mais reflexivos que exijam mais habilidades de estudo. Os estudantes têm que se habituar a pensar e para isso os conteúdos devem ser aplicados para compreensão e aplicação nas produções textuais."

A segunda pergunta tinha o objetivo de definir os gêneros textuais preferidos dos acadêmicos entrevistados na leitura. O gráfico 2 representa as respostas obtidas. 


\section{GRÁFICO 2}

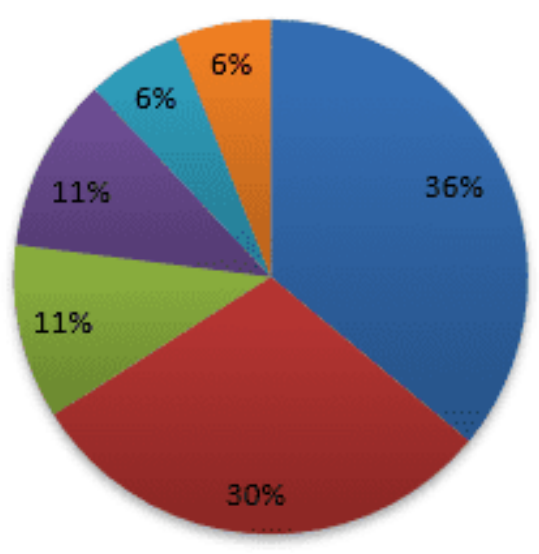

$$
\begin{aligned}
& \text { ש jornais/revistas } \\
& \text { n romance/ficção } \\
& \text { auto-ajuda } \\
& \text { aibis } \\
& \text { - poesias } \\
& \text { autobiografia }
\end{aligned}
$$

Fonte: Própria

Percebeu-se que, dos acadêmicos entrevistados, a maioria prefere a leitura de jornais e revistas. Tal fato se deve pela necessidade de informação imposta pela sociedade hodierna. Além disso, a leitura de jornais e revistas se apresenta de modo mais prático e acessível do que as leituras de romances e obras técnicas.

O questionamento seguinte fazia referência a quantidade de leituras realizadas por cada aluno em um determinado período. O gráfico 3 apresenta as resposta obtidas:

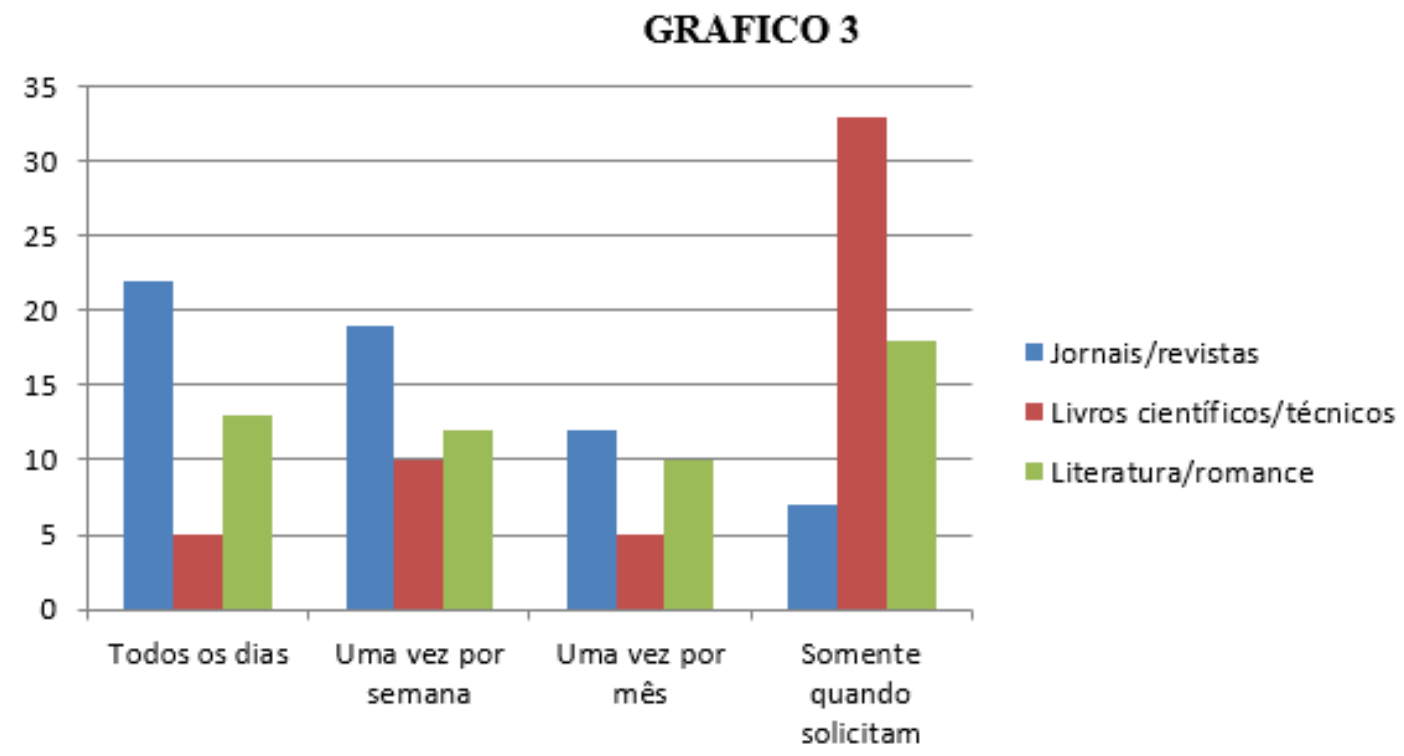

Fonte: Própria 
Observou-se que o tipo de leitura mais realizada pelos alunos entrevistados é a de jornais e revistas. Mesmo que exista uma necessidade de informação na sociedade hodierna, não se pode esquecer que para os textos produzidos no ensino superior são estabelecidos parâmetros, como a existência de referências textuais, em geral de livros técnicos, haja vista a confiabilidade nas informações encontradas neste tipo de obra. Como os acadêmicos não leem livros técnicos, a menos que algum professor solicite, eles desconhecem a formalidade desta escrita e, por isso, sentem tanta dificuldade na produção científica.

A pergunta número quatro, ao contrário das demais era uma pergunta com resposta aberta. Pedimos aos acadêmicos que escrevessem o nome da última obra lida e o seu autor. Dos 60 alunos que receberam o questionário, 18 informaram somente 0 nome do autor da obra lida, 13 informaram somente o título da obra, 18 responderam o título da obra e o seu autor, os outros 11 alunos não informaram nem o título da obra nem o nome do autor. Deste modo, pode-se estabelecer que aproximadamente $20 \%$ dos entrevistados não lembram qual foi a última obra que leram, o que nos leva a acreditar que estes alunos provavelmente não leem. Além disso, 38\% dos entrevistados informaram o mesmo título e autor de obra, o que reforça a tese de que os muitos alunos do ensino superior só leem o que é cobrado pela instituição de ensino.

O questionamento número 4 indagava se os alunos gostam de escrever. O gráfico 4 representa as respostas obtidas:

\section{GRÁFICO 4}
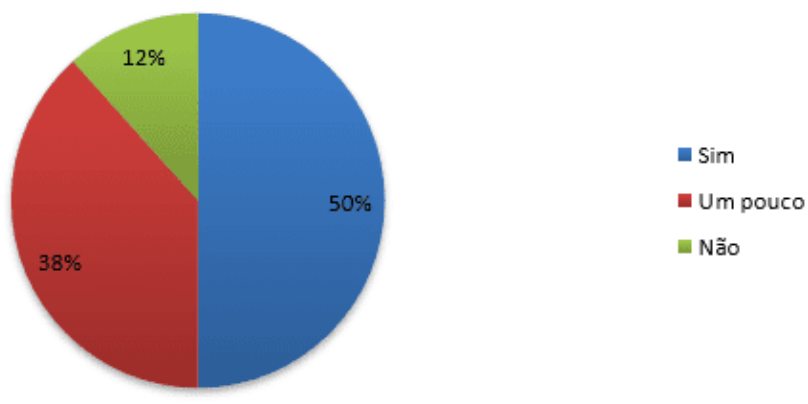

Fonte: Própria 
Observou-se que os percentuais de gosto pela leitura e pela escrita estão bem próximos, apesar de haver mais alunos informando que não gostam de escrever. Isto ocorre porque ao contrário da leitura, o ato de escrever não é visto como um hobby, e sim como uma obrigação. Além disso, escrever não é um ato pronto, acabado. Como já fora dito, escrever exige tempo, leituras, concentração, em resumo, escrever exige trabalho.

No sexto questionamento demandamos sobre a frequência com que cada aluno escreve que culminou no gráfico número 5.

\section{GRÁFICO 5}

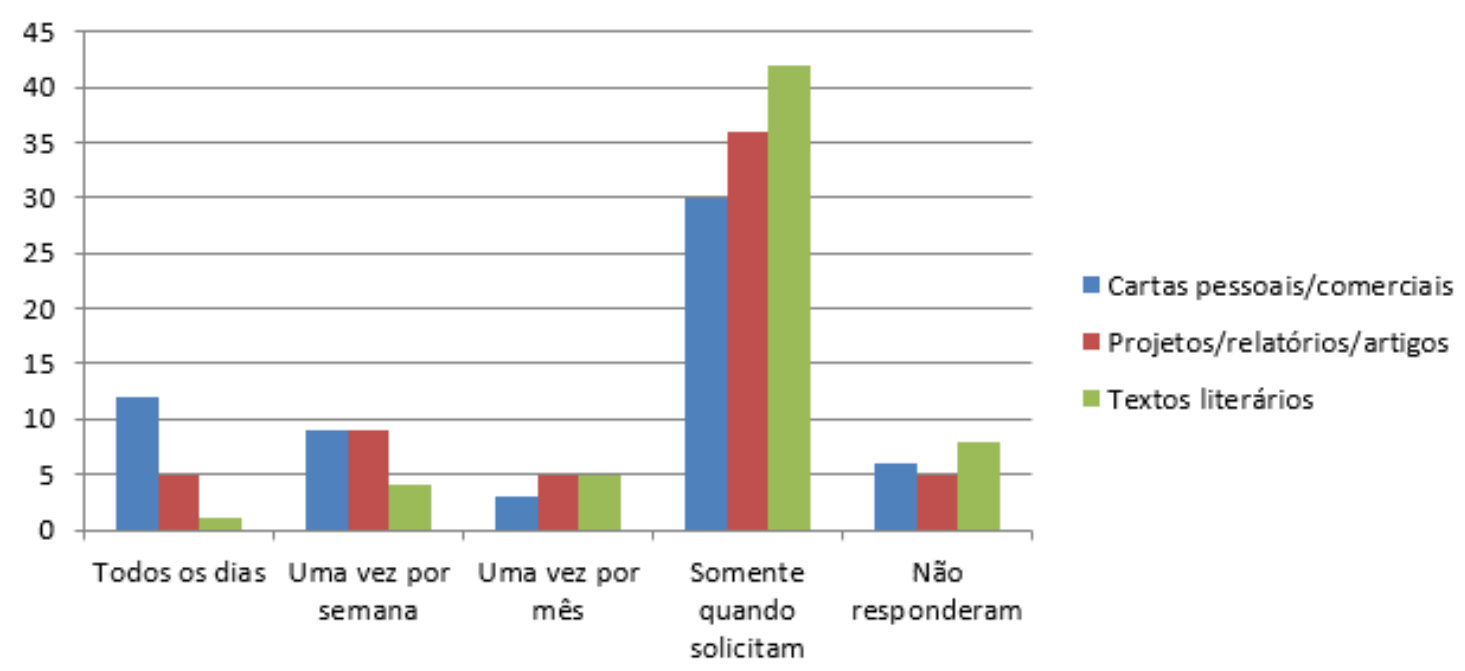

Fonte: Própria

Verificou-se por meio do gráfico acima que a maioria dos alunos entrevistados, em torno de $70 \%$, só escreve quando existe uma imposição sobre o ato, algum trabalho exigidos pelos docentes. Martins (2010) nos lembra que a escrita é um processo construtivo, não é algo pronto, finalizado, e, ao perceber-se que grande parte dos alunos entrevistados não escreve, acredita-se que parte desta deficiência está ligada ao processo. Como os acadêmicos escrevem pouco, não dominam o processo.

A pergunta número 7, assim como a número 4, era aberta. Pediu-se aos alunos que informassem o tema da última redação/artigo que haviam escrito. 32 dos entrevistados 
informaram o tema do último texto que produziram. 9 informaram que estavam escrevendo suas monografias. Os demais 24 alunos não responderam à pergunta. Assim, cabe-se pensar que estes alunos simplesmente não escreveram nada que fosse relevante nos últimos meses.

A oitava questão examinava com que frequência os discentes leem e reescrevem os textos que produzem. Abaixo estão reproduzidas em gráfico as respostas obtidas.

\section{GRÁFICO 6}

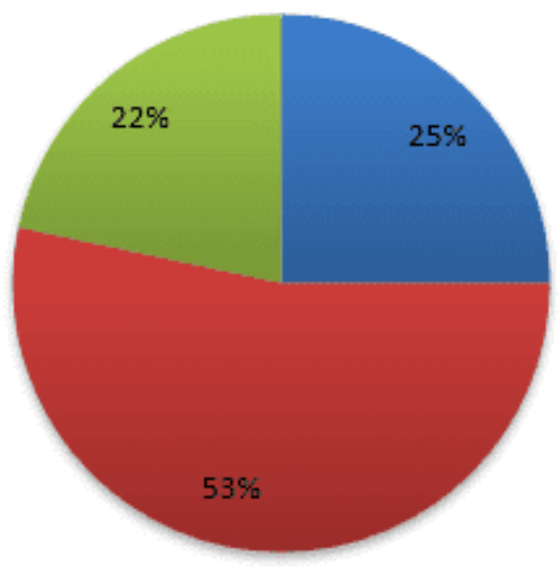

$$
\begin{aligned}
& \text { sempre } \\
& \text { às vezes } \\
& \text { nunca }
\end{aligned}
$$

Fonte: Própria

Constatou-se que dos entrevistados, $22 \%$ nunca reescrevem os textos que produzem; $53 \%$ reescrevem os textos algumas vezes - geralmente quando um professor exige. Apenas $25 \%$ dos acadêmicos possuem o hábito de ler o que escreveu, corrigindo erros e acrescentando informações. Fica claro assim o motivo de haver tantos problemas nos textos escritos por estes jovens. Faltam leituras, prática da escrita e hábito de reescrever.

A última questão pedia para os entrevistados avaliarem os textos que escrevem. $O$ gráfico 7 apresenta as respostas obtidas. 


\section{GRÁFICO 7}

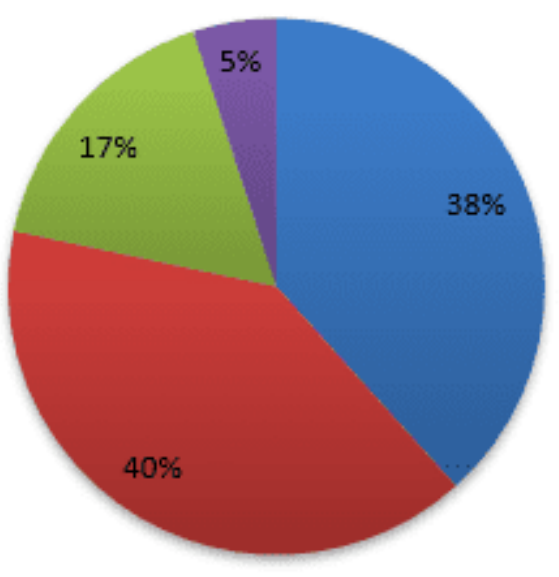

Bons

Medianos

Não avalio minhas produções

não responderam

Fonte: Própria

Dos discentes que responderam ao questionário, 38\% avaliaram suas produções como boas; $40 \%$ responderam que seus textos são medianos; $17 \%$ disseram que não avaliam suas produções; e 5\% não responderam a questão. O que se pode concluir das respostas obtidas neste quesito é que existem produções boas no nível superior, contudo existe um número grande de alunos que sentem medo de dizer que seus textos são bons ou ruins, porque simplesmente falta a eles conhecimento textual para identificar suas falhas e acertos, e, consequentemente corrigi-las.

\section{CONCLUSÃO}

Ao realizar a leitura dos questionários respondidos pelos alunos, percebeu-se que mais da metade destes alunos não gostam de ler. Embora a leitura não represente fator decisivo na escrita, sua falta diminui o repertório argumentativo de quem escreve. Além disso, as pessoas que não cultivam o hábito da leitura sentem mais dificuldade de realizá-la quando solicitado para realização de um trabalho, pois o nível de concentração de quem não lê tende a ser menor.

Outro ponto importante da pesquisa refere-se ao tipo de leitura que os acadêmicos realizam. Apesar dos gêneros literários citados serem variados, a maioria dos 
entrevistados informou que lê apenas jornais, isto explica a dificuldade que muitos possuem para redigir textos mais elaborados, como o texto poético e o científico.

Além disso, observou-se que, muitos dos universitários entrevistados, julgam os textos que produzem como bons, porém, os mesmos afirmam não possuir o hábito de lê-los e reescrevê-los, a não ser que seja solicitado. Percebe-se que tal prática é comum tanto no ensino fundamental e médio, como no ensino acadêmico, pois, a maior parte dos docentes não solicita que os alunos reescrevam seus textos, o que leva a crer que os textos produzidos na universidade em geral sirvam apenas como instrumento de avaliação, transformando o espaço do texto em algo pequeno, tendo em vista as dimensões que ele poderia alcançar.

\section{REFERÊNCIAS}

CAVALCANTI, Jauranice Rodrigues. Professor, leitura e escrita. São Paulo: Contexto, 2010.

CUNHA NB, SANTOS AAA. Relação entre a compreensão da leitura e a produção escrita em universitários. Psicol Reflex Crit. (Porto Alegre) 2006, v. 19, n. 2 [citado em 2007 mai 25], $\quad$ p. 237-245. Disponível em: http://www.scielo.br/pdf/prc/v19n2/a09v19n2.pdf acessado em 08/05/2012.

DUARTE, Rosália. Pesquisa qualitativa: reflexões sobre o trabalho de campo. Cadernos de pesquisa, n. 115, p 139-154, março/2002.

FONTANA, Niura Maria; PORSCHE, Sandra Cristina. Leitura, escrita e produção oral: proposta para o ensino superior. Caxias do Sul: EDUCS, 2011

KRÁS, Cléa Silvia Biasi. A interdependência entre a leitura e a produção escrita. Disponível em: http://revista.ulbratorres.com.br/artigos/artigo08.pdf, acessado em 08/05/2012.

MANGAS, Catarina F. SANCHEZ, José L. R. A dislexia no ensino superior: características, consequências e estratégias de intervenção. Disponível em: 
https://iconline.ipleiria.pt/bitstream/10400.8/413/1/3635Frade.pdf, acessado em 08/05/2012.

MARQUESIN, Denise F. B; BENEVIDES, Claudio R.; BAPTISTA, Denise C. Leitura e Escrita no Ensino Superior. Revista de Educação. (Anhanguera) 2011, v. 14, n. 7. Disponível no endereço eletrônico: https://revista.pgsskroton.com/index.php/educ/article/ viewFile/1801/1714, acessado em 08/05/2012.

MOTTA, Íride Luiza de Oliveira Murari. Dificuldades na escrita dos alunos de Ensino Superior: um análise das narrativas escritas dos alunos da faculdade Eduvale. Disponível em: http://www.eduvalesl.edu.br/site/edicao/edicao-27.pdf acessado em 08/05/2013.

OLIVEIRA, K. L, SANTOS, A. A. A. Compreensão em leitura e avaliação da aprendizagem em universitários. Psicol. Reflex Crit. (Porto Alegre) 2005, v. 18, n. 1 [citado em 2007 mai 25], p.118-124. Disponível em: http://www.scielo.br/pdf/prc/v18n1/24825.pdf, acessado em 08/05/2012.

PRIMI R., SANTOS A. A. A., VENDRAMINI C. M. Habilidades básicas e desempenho acadêmico em universitários ingressantes. Estud Psicol. (Natal) 2002, v. 7, n. 1 [citado em 2007 mai 25]. p.47-55. Disponível em: http://www.scielo.br/pdf/epsic/v7n1/10953.pdf, acessado em 08/05/2012.

RAMIRES, Vicentina. Leitura e produção escrita de universitários. Disponível em: http://www.revistadeletras.ufc.br/rl24Art07.pdf, acessado em 08/05/2012.

SAMPAIO I. S., SANTOS A. A. A. Leitura e redação entre universitários: avaliação de um programa de intervenção. Psicol Estud. (Maringá) 2002, v. 7, n. 1 [citado em 2007 mai 25], p.31-38. Disponível em: http://www.scielo.br/pdf/pe/v7n1/v7n1a04.pdf

2. Disponível no endereço eletônico http://revista.ulbratorres.com.br/artigos/artigo08.pdf, consultado em 08/05/2012. 
Enviado: Abril, 2019.

Aprovado: Outubro, 2019. 